\title{
Variations in PEFR among Males and Females With Respect To Anthropometric Parameters
}

\author{
${ }^{1}$ Dr. Jayanti Mishra*, ${ }^{2}$ Dr. Soumya Mishra, ${ }^{3}$ Dr. Sudeep Satpathy, ${ }^{4}$ Dr. Magna \\ Manjareeka, ${ }^{5}$ Dr. Prakash Kumar Nayak, ${ }^{6}$ Dr. Prabhabati Mohanty \\ 1,2,3,4,5,6 Department of Physiology, Kalinga Institute of Medical Sciences, Bhubaneswar, Odisha
}

\begin{abstract}
Of the many factors regulating Peak expiratory flow rate (PEFR), anthropometric determinants such as height and weight play an important role. PEFR among males and females also show variations in anthropometric parameters. This study aims at analysing the factors determining PEFR in 181 healthy young adults with the help of "The Peak", Individualised Peak flow meter from Multispiro Inc. The subjects were categorised into groups based on their difference in height and weight. Three PEFR readings were taken from each individual and the best of three readings was considered. The variations of PEFR with respect to height and weight were determined separately. There was a positive correlation of PEFR with height and weight in the young adult males and females. In the males PEFR correlated better with height and in the females it correlated better with weight.
\end{abstract}

Key Words: Spirometry, ventilatory function, peak flow meter, height and weight variations with PEFR, sex correlation with PEFR.

\section{Introduction}

Peak Expiratory Flow Rate (PEFR) as a measurement of ventilatory function was introduced by Adorn in 1942, and was accepted in 1949 as an index of spirometry [1]. By definition, it is "the largest expiratory flow rate achieved with a maximally forced effort from a position of maximal inspiration, expressed in litres/min" [2]. PEFR is considered as the simplest index of pulmonary function to assess the ventilatory capacity. It is effort dependent and reflects mainly the calibre of the bronchi and larger bronchioles, which are subjected to reflex bronchoconstriction [2]. It is relatively a simple procedure, and may be carried out in the field using portable instruments. The average PEFR of healthy young Indian males and females are around 500 and 350 litres/minute respectively [3]. The PEFR reaches a peak at about 18-20 years, maintains this level up to about 30 years in males, and about 40 years in females, and then declines with age. The peak flow meter which is a reliable and safe, bedside instrument fulfils the need of assessing the ventilatory function. The portability and simplicity of the peak flow meter make it particularly suitable for studies of respiratory function $[4,5]$. There have been reports on the variations of various ventilatory parameters with anthropometric determinants like height and weight in previous studies. Previously various scientific studies have been carried out to relate PEFR to height and weight of the subjects [6, 7, 8, 9]. Conflicting reports have also been documented [10].

The present study has been taken up to look into the relationship between PEFR and anthropometric parameters like height and weight in males and females and determining which factor has a stronger association with PEFR. The subjects were chosen around the age of 18-20years as during this age, PEFR is recorded at its peak levels and has least variations.

\section{Materials and Methods}

The 181 healthy adults (66 males and 115 females) selected for this study were among the students of the Kalinga Institute of Medical And Dental Sciences, Bhubaneswar, Odisha who consented to participate in the study. The study was undertaken in the Department of Physiology, Kalinga institute of Medical Sciences, Bhubaneswar, Odisha after the procurement of permission from the Human Ethics Committee of the Institute. The criteria satisfied by the subjects before being accepted for the study were:

(a) No history of cardio - pulmonary disease, as evidenced from the questionnaires filled out by all subjects prior to the study. Such information was further confirmed by oral interview and clinical examination;

(b) Availability and capacity to cooperate adequately for the duration of the study;

(c) They were all non - smokers;

(d) No history of any drug intake which could possibly affect the lung functioning.

The subjects were asked to refrain from caffeine intake and careful measures were taken to avoid any exposure to smoking or any form of air pollutant 24 hours prior to the study. The subjects were advised to have light breakfast in the morning and avoid wearing any tight clothes. They were then made to relax physically and mentally for 15 minutes and vital parameters like blood pressure, heart rate, respiratory rate were recorded. Standing height was measured in centimetres with a standard height measuring rod; weight was measured in 
kilograms with calibrated Libra Weighing Scale. PEFR was measured with the subject comfortably seated during the same time of the day for all subjects (i.e. between 10am - 11am) to avoid diurnal variations. It is determined in litres/minute with the help of "The Peak", Individualised Peak flow meter from Multispiro Inc. Instructions and method of carrying out the test was demonstrated to all the subjects individually. The subjects were asked to inspire deeply, and then blow into the instrument's mouthpiece with nostrils closed. Each subject made three PEFR measurement manoeuvres since this requires practice and maximum effort, and the highest value was considered $[3,11]$.

Considering the differences between the maximum and minimum value of height recorded, the subjects were grouped into different ranges of height. Similar procedure was followed for categorizing the subjects according to their weight. Unpaired t-test was used to determine the differences between the PEFR, height and weight of male and female subjects. p-value less than or equal to $0.05(\mathrm{p} \leq 0.05)$ was considered as statistically significant. Correlation coefficient ( $r$ ) was calculated between PEFR and different parameters separately for male and female subjects. All statistical analysis was done using Graph Pad Prism 5 software.

\section{Results}

The mean age of the male subjects was recorded as $18.93 \pm 1.23$ years and the mean age of the female subjects was $18.47 \pm 0.77$ years. Table 1 shows the male subjects grouped according to their height and the mean PEFR value recorded in each group. We observe a gradual trend of increasing PEFR with respect to increasing height.

TABLE 1: Variations of PEFR with height in normal young adult males

\begin{tabular}{|l|l|l|}
\hline Height $(\mathbf{c m})$ & No. of persons & PEFR (Mean \pm S.D) L/min \\
\hline $\mathbf{1 4 6}-\mathbf{1 5 0}$ & 01 & $360.00 \pm 00.00$ \\
\hline $\mathbf{1 5 1 - 1 5 5}$ & 01 & $490.00 \pm 00.00$ \\
\hline $\mathbf{1 5 6}-\mathbf{1 6 0}$ & 01 & $290.00 \pm 00.00$ \\
\hline $\mathbf{1 6 1}-\mathbf{1 6 5}$ & 06 & $433.33 \pm 47.18$ \\
\hline $\mathbf{1 6 6}-\mathbf{1 7 0}$ & 14 & $435.71 \pm 108.39$ \\
\hline $\mathbf{1 7 1}-\mathbf{1 7 5}$ & 16 & $430.62 \pm 78.01$ \\
\hline $\mathbf{1 7 6}-\mathbf{1 8 0}$ & 19 & $505.79 \pm 101.12$ \\
\hline $\mathbf{1 8 1}-\mathbf{1 8 5}$ & 06 & $563.33 \pm 90.92$ \\
\hline $\mathbf{1 8 6}-\mathbf{1 9 0}$ & 02 & $390.00 \pm 14.14$ \\
\hline
\end{tabular}

Correlation coefficient $(\mathrm{r})=0.302 *, \mathrm{~N}=66$

$*=$ positive correlation

Table 2 shows the male subjects grouped according to their weight and the mean PEFR recorded in each group. With weight also we see a proportionate increasing trend of PEFR values.

TABLE 2: Variations of PEFR with weight in normal young adult males

\begin{tabular}{|l|}
\hline Weight (kg) \\
\hline $36-40$ \\
\hline $41-46$ \\
\hline $46-50$ \\
\hline $51-55$ \\
\hline $56-60$ \\
\hline $61-65$ \\
\hline $66-70$ \\
\hline $71-75$ \\
\hline $76-80$ \\
\hline $81-85$ \\
\hline $86-90$ \\
\hline $91-95$ \\
\hline $96-100$ \\
\hline
\end{tabular}

\begin{tabular}{|c|c|}
\hline No. of persons & PEFR (Mean \pm S.D) L/min \\
\hline 00 & $000.00 \pm 00.00$ \\
\hline 00 & $000.00 \pm 00.00$ \\
\hline 04 & $380.00 \pm 28.28$ \\
\hline 06 & $468.33 \pm 122.38$ \\
\hline 10 & $416.00 \pm 81.13$ \\
\hline 06 & $416.66 \pm 45.46$ \\
\hline 09 & $467.77 \pm 96.01$ \\
\hline 13 & $459.23 \pm 91.42$ \\
\hline 09 & $543.33 \pm 124.39$ \\
\hline 03 & $500.00 \pm 132.28$ \\
\hline 04 & $457.50 \pm 131.24$ \\
\hline 01 & $520.00 \pm 00.00$ \\
\hline 01 & $510.00 \pm 00.00$ \\
\hline
\end{tabular}

$\mathrm{r}^{*}=0.28 \quad \mathrm{~N}=66$

$*=$ positive correlation 
From Table 1 and Table 2 we find that in case of males, a stronger association exists between PEFR and height as compared to PEFR and weight. Table 3 shows the female subjects grouped according to their height and the mean PEFR recorded in each group.

TABLE 3: Variations of PEFR with height in normal young adult females

\begin{tabular}{|l|l|l|}
\hline Height $(\mathrm{cm})$ & No. of persons & PEFR (Mean \pm S.D) L/min \\
\hline $\mathbf{1 4 6}-\mathbf{1 5 0}$ & 10 & $271.00 \pm 51.74$ \\
\hline $\mathbf{1 5 1 - 1 5 5}$ & 30 & $269.33 \pm 65.17$ \\
\hline $\mathbf{1 5 6}-\mathbf{1 6 0}$ & 15 & $288.66 \pm 54.75$ \\
\hline $\mathbf{1 6 1}-\mathbf{1 6 5}$ & 38 & $293.68 \pm 57.63$ \\
\hline $166-170$ & 15 & $324.66 \pm 57.67$ \\
\hline $171-175$ & 05 & $320.00 \pm 53.38$ \\
\hline $176-180$ & 02 & $255.00 \pm 106.06$ \\
\hline $181-185$ & 00 & $000.0 \pm 00.00$ \\
\hline $186-190$ & 00 & $000.00 \pm 00.00$ \\
\hline
\end{tabular}

$\mathrm{r}^{*}=0.209 \quad \mathrm{~N}=115$

$*=$ positive correlation

Table 4 shows the female subjects grouped according to their weight and the mean PEFR recorded in each group.

TABLE 4: Variations of PEFR with weight in normal young adult females

\begin{tabular}{|l|l|l|}
\hline Weight $(\mathbf{k g})$ & No. of persons & PEFR (Mean \pm S.D) $\mathbf{L} / \mathrm{min}$ \\
\hline $\mathbf{3 6 - 4 0}$ & 04 & $262.50 \pm 61.84$ \\
\hline $\mathbf{4 1 - 4 5}$ & 12 & $237.50 \pm 67.30$ \\
\hline $\mathbf{4 6 - 5 0}$ & 20 & $276.00 \pm 57.06$ \\
\hline $\mathbf{5 1 - 5 5}$ & 28 & $295.00 \pm 50.51$ \\
\hline $\mathbf{5 6}-\mathbf{6 0}$ & 15 & $308.00 \pm 61.32$ \\
\hline $\mathbf{6 1 - 6 5}$ & 12 & $304.16 \pm 52.82$ \\
\hline $\mathbf{6 6}-\mathbf{7 0}$ & 13 & $293.07 \pm 72.27$ \\
\hline $\mathbf{7 1 - 7 5}$ & 06 & $306.66 \pm 66.53$ \\
\hline $\mathbf{7 6}-\mathbf{8 0}$ & 04 & $345.00 \pm 19.15$ \\
\hline $\mathbf{8 1 - 8 5}$ & 00 & $000.00 \pm 00.00$ \\
\hline
\end{tabular}

$\mathrm{r}^{*}=0.29 \quad \mathrm{~N}=115$

*=positive correlation

From Table 3 and Table 4 we find that in case of females, a stronger association exists between PEFR and weight as compared to association between PEFR and height. Table 5 summarizes the mean values of height, weight and PEFR of males and females.

TABLE 5: Anthropometry and PEFR in healthy young adults

\begin{tabular}{|llll|}
\hline Subjects & $\begin{array}{l}\text { Height in } \mathbf{c m} \\
(\text { Mean } \pm \text { SD })\end{array}$ & $\begin{array}{l}\text { Weight in kgs } \\
(\text { Mean } \pm \text { SD })\end{array}$ & $\begin{array}{l}\text { PEFR in L/min } \\
(\text { Mean } \pm \text { SD })\end{array}$ \\
\hline Males $(\mathbf{N = 6 6 )}$ & $172.92 \pm 7.29$ & $68.68 \pm 11.51$ & $462.12 \pm 100.79$ \\
\hline Females $(\mathbf{N = 1 1 5 )}$ & $159.34 \pm 6.94$ & $56.74 \pm 10.29$ & $289.30 \pm 60.87$ \\
\hline $\mathbf{t}$ & 12.44 & 7.19 & 11.65 \\
\hline P value & $<0.0001 *$ & $<0.0001 *$ & $<0.0001 *$ \\
\hline
\end{tabular}

$*=$ statistically significant

\section{Discussion}

A number of factors influence PEFR in normal subjects. Weight and height are the common ones. PEFR is best correlated to height and weight, even though other physical factors such as age and body surface area may also correlate well [13]. Pulmonary function tests (PFTs) are one of the indicators of the health status of the individuals and could be used as a tool in general health assessment [14, 15]. It is influenced by body build, muscular strength and nutritional status thereby showing a higher value of PEFR in males as compared to females whose body framework is fragile and muscle mass is replaced with more of fat deposits. This calls for further studies on how body mass index and body composition affects the PEFR. 
The values of PEFR obtained in this study were within the normal ranges for the healthy adult male (360 $900 \mathrm{~L} / \mathrm{min})$ and female $(168-600 \mathrm{~L} / \mathrm{min})$ populations [12]. The mean values of height, weight and PEFR were higher for males than females $(\mathrm{P}<0.0001)$. This also points to positive anthropometric association with PEFR. Our study showed that in males, PEFR significantly increases with height $(r=0.302)$ and weight $(r=0.282)$, which is in agreement with the reports of certain other investigators $[6,7,8,9]$.

The limitations of the study are - (1) Improper distribution of subjects in the various height-wise and weightwise categorization. This could have been taken care of by increasing the population size and random selection of subjects from general population instead of students of medical school. (2) Difficulty on the part of some subjects to record the PEFR correctly leading to lower values even after innumerable demonstrations and repeated practice by the subjects. To avoid such a scenario, medical students were selected for the study anticipating that they would understand the procedure of PEFR recording quicker and much effectively then the general population. Though the magnitude of the problem was greatly suppressed, few students still showed difficulty in performing the manoeuvres for measurement of PEFR.

\section{Conclusion}

It is concluded that PEFR shows positive correlation with anthropometric determinants like height and weight. In the males PEFR correlates better with height and in the females it correlates better with weight.

\section{Conflicts Of Interest}

There is no conflict of interest.

\section{References:}

[1] Jain SK, Kumar R, Sharma DA. Peak Expiratory flow rates (PEFR) in healthy Indian adults: A statistical evaluation -I. Lung India 1983; 3: 88-91.

[2] American Thoracic Society: Standardization of Spirometry; 1994 update. Amer J Respir \& Critical Care Med 1995; 152: $1107-1136$.

[3] Dikshit M B, Raje S, Agarawal M J. Lung functions with spirometry : An Indian perspective-I. Peak expiratory flow rates ; Indian J Physiol Pharmacol $2005: 49$ (1): 8-18.

[4] Pande JN, Mohan A, Khilani S, Khilani GC. Peak expiratory flow rate in school going children. Indian J Chest Dis \& Allied Sci 1997; 39: 87-95.

[5] Venkatesan EA, Walter S, Ray D. An evaluation of the Assess peak flow meter on human volunteers. Indian J Physiol Pharmacol 1994; 38: 285-288.

[6] Azah, N., Antai, E.J., Peters, E.J., Osim,E.E. (2002). Normal lung function values of Nigerian children aged 6 - 16 years. Nig. J. Physiol. Sci. 17(1-2): $74-75$.

[7] Elebute, E.A., Femi-Pearse, D. (1971). Peak Flow rate in Nigeria: Anthropometric determinants and usefulness in assessment of ventilatory function. Thorax. 26: 597

[8] Ali, M.A. (1983). Ventilatory functions in non- smoking healthy Nigerian adults. W.Afr. J. Med. 2(1): $1-8$.

[9] Jaja, S.I., Ojo, G.O. (1983). Peak flow rate in young Nigerian adults. Nig. J. Physiol. Sci. 1(2): $24-30$.

[10] Gupta CK, Neeraj Mathur . Statistical models relating peak expiratory flow rates to age, height, and weight in men and women. Journal of Epidemiology and Community Health, 1982, 36, 64-67

[11] Aggrawal AN, Gupta D, Kumar V, Jindal SK. Assessment of diurnal variability of peak expiratory flow in stable asthmatics. J Asthma 2002; 39: 487-491

[12] M. I. Ebomoyi,v. I. Iyawe. Variations of peak expiratory flow rate with anthropometric determinants in a population of healthy adult nigerians. Nigerian Journal of Physiological Sciences 20 (1-2): 85-89@ Physiological Society of Nigeria, 2005

[13] Gupta CK, Mishra G, Mehta SC, Prasad J. On the contribution of height to predict lung volumes, capacity diffusion in healthy school children of 10-17 yr. Indian J Chest Dis Allied Sci 1993; 35:167-177.

[14] Holger J, Schunemann, Joan Dorn, Brydon JB, Grant, Warren Winkelstein, Jr., Maurizio Trevisian. Pulmonary function is the long term predictor of mortality in the general population: 29 years follow-up of the buffalo health study. Chest 2000; 118: 656-64.

[15] Prakash S, Meshram S, Ramtekkar U. Athelets, yogis and individual with sedentary life styles; do their lung function differ? Indian J Physiol Pharmacol 2007; 51: 76-80. 